\title{
The Relationship between the intellectual security and the motivation for achievement of university students
}

\section{$\mathrm{N}$ emaa $\mathrm{N}$ ady Abd El-Samee (PhD) Eman salah Mohamed Elsayed (PhD)}

Assistants Professor social work with individual and families Helwan University, Cairo, Egypt 

The Relationship between the intellectual security and the motivation for achievement of university students

\section{Nemaa Nady Abd El-Samee (PhD)}

\section{Eman salah Mohamed Elsayed (PhD)}

Assistants Professor social work with individual and families Helwan University, Cairo, Egypt

\section{Abstract:}

This study aimed to determine the relationship between intellectual security and the motivation for achievement of university students. It also aimed to identify the indicators of the role of social workers in enhancing the intellectual security and motivation of university students. We selected a purposive sample of (358) students (first year), (104) male and (254) female.

The study concluded that there is a positive and statistically significant relationship between intellectual security in its various dimensions (citizenship, religious, intellectual, security, heritage, moral and media dimensions), and the motivation of university students, at a level of significance of (0.01). There are statistically significant differences between the mean scores of males and females on the scale of intellectual security of university students, in its various dimensions, in favour of males, while there are no statistically significant differences between the mean scores of males and females on the scale of motivation of university students in its various dimensions.

\section{Key words:}

Intellectual security - motivation for achievement - university students

\section{Introduction:}

Young people are the future of society, forming the most important element in the planning process for any society that seeks to develop in the future. This stage of human life is one of the most important as this is when young people discover a variety of human skills, whether psychological, social or mental, to help them manage the affairs of their lives and relationships with those around them. The number of Egyptians aged (18-29) numbered 20.2 million in 2018, representing $21 \%$ of the population. The proportion of males was $50.6 \%$, with females making up 49.4\%. (Central Agency for Public Mobilization and Statistics, 2018)

The 21 st century has come to be known as the generation of the young. It is important that this generation be on the right path to development. In recent years many factors such as developments in 
technology, changing educational systems, social media, social networking and globalization are influencing the overall behavior of this generation. The process of globalization is growing day by day, having a significant influence on young people. The chances of maladjustment are high if there is a lack of proper guidance. But factors including moral values, emotional intelligence, family environment, motivation, and social relationships play a major role in the healthy adjustment of an individual. (Naik, D., \& Ahirrao, K. D., 2018, p.68)

Students, and in particular university students, are among the most important sectors of youth to which the State pays more care and attention (Fahmy, 2012, p129). Where the number of students enrolled in higher education reached 3,030,754 students in 2016-17, the number of male students was 578,662 or $52.1 \%$, while the number of female students reached 145,202 or 47.1\%. (Central Agency for Public Mobilization and Statistics, 2018)

Undergraduate education is one of the most important educational stages concerned with maintaining security and stability, and achieving intellectual security for this category, enabling them to reap the benefits of all society. Undergraduate students, if guided well, will create the emergence of a sound society protecting against the intellectual extremism of university students (Al-Anani, 2013, p216). The study of (Mohammed, 2013) aimed to identify the role of university in promoting the concept of intellectual security among university students, and highlight the role of faculty members in activating intellectual security. The study concluded that teaching students with a good intellectual education through the consolidation of the principles of moderation will go on to create moderation in their beliefs, actions and words.

The study of (Mansour, 2017) aimed to evaluate the role that universities should play in helping to achieve intellectual security from the perspective of students and faculty members. The students agreed on the causes of intellectual deviation to a medium degree and the role of curricula in achieving intellectual security to a high degree. The role of faculty members in achieving intellectual security to a medium degree, and student activities to a medium degree

The study of (Awad, 2017) aimed to determine the role of social workers in enhancing the national identity of university students, and to identify the mechanisms used by social workers to enhance the intellectual security of young people. The results of the 
study showed that the majority of the study sample was not interested in the activities of the committees of the Union. Participation in and focus was on academic achievement in preparation for graduation, in addition, a lack of sufficient information on intellectual security by the group social worker was available.

Intellectual security aims to develop the mind and protect it from deviation, strengthening it in the face of extremism or influences that may make an individual a threat to security and stability. Intellectual security will address any imbalance or disturbance of the mind and attempt to correct it in order to secure the state and society in the face of the resulting problems caused by an individual's extreme visions and ideas. (Al-Khatib, 2015, p 4). In this regard, the study of (Ali, 2017) aimed to determine the nature of the relationship between intellectual security and emotional intelligence and decision-making among Cairo University students, and to identify the differences between university students according to the study variables (gender and specialization). The study found a significant correlation between intellectual security and emotional intelligence and decision-making among university students, and the presence of statistically significant differences between male and female students in the variables of the study, with these differences tending to favor females in intellectual security.

Achieving the intellectual security of individuals will contribute to the peaceful coexistence of people, positively reflecting the stability of society and the preservation of its capabilities (achieving social and psychological stability), as well as achieving religious and moral stability through moderation and a sense of belonging to the culture of the nation and dialogue with the world. If the intellectual security of university students is achieved, it will have a positive impact on their community (Al-Ghamdi, 2012, p237). In this regard, the study of (Arab, 2018) aimed to identify the nature of the relationship between social responsibility and intellectual security, as well as the relationship between belonging and intellectual security. The study concluded that there is a statistically significant correlation between national belonging and intellectual security as well as social responsibility and intellectual security.

Due to the rapid progress and development of means of communication, knowledge and information of all kinds, the spread of satellite channels, the media, the internet and the openness to the world, the world is becoming a small village. This has had an impact 
on societies, leading to the penetration of multiple intellectual trends within our society. Social networks have positive and negative implications in the multidirectional dimensions of the intellectual security of university students. The study of (Al-Hazani, 2016) aimed to determine the effect that social networks have in enhancing the intellectual security of university students. The approval of all terms reached the highest rate in the political effects $85.3 \%$, social and psychological effects $74.7 \%$, and religious and moral implications $72.4 \%$.

In this regard, the study of (Jad \& Ahmad, 2019) aimed to determine the relationship between the use of social networking sites and intellectual security among students of social work. The study concluded that there are no statistically significant differences between the mean scores of social work students (male or female) using social networking sites and their impact on the social dimension of intellectual security. However, there were statistically significant differences between the mean scores of social work students (male and female) using social networking sites and their impact on the religious, political and economic dimensions of intellectual security.

In this context, cognitive theory aims to modify the irrational thoughts of university students as their intellectual security is determined by their thinking, beliefs and expectations. Therefore, the high or low level of intellectual security is due to those ideas, whether rational or irrational, which affects their emotions and then their behaviors.

Motivation for achievement is an important factor in guiding an individual's behavior towards oneself, and affirming where an individual feels the need to improve himself through what he accomplishes, what he achieves, his goals, a better way of life, and greater levels of his human existence (Zaher, 2018, p214).

Modern society, with its rapidly changing technologies and intensive development, requires a person to constantly acquire new knowledge, attainments and skills. Therefore, great importance is given to the achievement of motivation in the life of modern man, which facilities his constant development both professionally and personally, helping him to realize himself and find his place in society. Motivation for achievement is a reliable predictor of academic achievement in school and university, as well as success in professional life (Berdnikova, 2018, p152). The study of (Salem \& Qambil \& Al-Khalifa, 2012) aimed to determine the correlation 
between motivation for achievement, the level of ambition and the academic achievement of university students in Sudan. The results of the study found a statistically significant correlation between motivation and the level of ambition of participants, but that there is no significant correlation between motivation and academic achievement.

Attention to the motivation for achievement among university students is one of the most important objectives that the university believes will contribute to the service of in society and to the achievement of scientific progress. The study of (Al-Ahmad, 2017) aimed to determine the nature of the correlation between the motivation for achievement and irrational thinking, and the results of the study found that the level of motivation among the members of the research sample was at a medium degree. The absence of significant differences on the measure of motivation for achievement were attributed to the variable of the school year and sex variable.

The study of (Hussein, 2017) aimed to identify the motivation for achievement among university students - and the differences in the motivation for achievement among university students according to sex variables (male and female) and specialization (scientific human), and to determine the correlation between motivation and the future ideas of students. The study results found no statistical differences of motivation for achievement of university students according to sex variables (males and females) and specialization (scientific and human), and a correlation between motivation for achievement and future ideas among university students.

(Naik \& Ahirrao, 2018) aimed to explore the relationship between emotional intelligence (EI) and motivation in adult university students as well as the comparison of males and females with respect to emotional intelligence and motivation. The results of the study found a positive and statistically significant relationship between emotional intelligence and motivation of college students. There are differences between the sexes in emotional intelligence, where females score higher than males and the results of the study pointed to the existence of statistically significant differences in the levels of motivation in both sexes.

The study of (Turki \& Jdaitawi and Sheta, 2018) also investigated the impact of social connectedness, motivation and emotional-social learning upon the adjustment of students in a university context. In addition, this study looks into the differences in motivation and 
emotional- social learning levels between the genders. According to the findings, gender differences were noted in terms of emotionalsocial learning levels, but not in terms of motivation and social connectedness.

The behavioral theory of behavior (motivation for achievement) is seen as a visible and observable behavior that the student learns from the environment in which he or she lives and becomes habitually repeated through reinforcement and modeling. The basic objective of behavioral theory is to increase the desired behavior patterns (motivation for achievement) in order to achieve more Compatibility between the student and the surrounding environment.

Through the previous presentation, the problem of the study can be crystallized in the following questions:

1. Is there a fundamental relationship between intellectual security and the motivation for achievement of university students?

2 - Are there differences between the mean scores of male and female students in the variables of the study (intellectual security, motivation for achievement)?

\section{Study Objectives:}

1- Determine the nature of the relationship between intellectual security and the motivation for achievement of university students.

2 - Identify indicators of the role of social workers in promoting intellectual security and the motivation for achievement of university students.

\section{Study Concepts}

\section{1- Intellectual security:}

Hariz (2005) defined intellectual security as providing freedom and democracy as a condition for launching creative and constructive thought. It is a minimum of freedom of opinion and expression with the aim of achieving stability and development resulting from dialogue between all cultures, civilizations and religions and to promote understanding and tolerance among all nations and peoples (Al-Khathlan, 2017, p68).

Intellectual security means the integrity of human thought and understanding, and the absence of prejudiced beliefs and misconceptions that lead to deviation from moderation, and the achievement of moderation in understanding and thinking whether in religious or worldly matters (Al-Hoshi 2017, p25). 
Intellectual security is also defined as the integrity of university student perception of misconceptions and intellectual deviations. Thus, the university student achieves personal stability, through which society is strengthened socially, intellectually and psychologically, and has a significant positive impact on the follow-up of intermediate approaches to thinking (Ali, 2017, p152).

The concept of intellectual security refers to the protection of the minds of individuals from all misconceptions and beliefs that contradict the belief that society owes, and the need to exert efforts from all community institutions to achieve this protection in order to preserve the ideas of young people from deviation (Al-Wahsh, 2018, p128).

Theoretical definition of intellectual security: securing university students' thinking, protected from immoral ideas, in order to achieve personal stability and prepare the individual as an effective member of society, and to fortify his mind with sound ideas related to the dimensions of intellectual security (citizenship, religious, intellectual, security, heritage, moral, media).

The concept of intellectual security is measured procedurally to the degree that a university student obtains on the dimensions of the intellectual security scale.

\section{2- Motivation:}

Motivation for achievement is a multi-dimensional, virtual construction that guides an individual and leads him to carry out his duties accurately, systematically and independently. He can work to overcome obstacles he encounters, which gives him confidence and peace of mind, in order to achieve the standards of excellence needed to achieve his future goals (Ghanimat \& Olimat 2012, p30).

Mohamed (2015) defined motivation for achievement as the desire of the individual to succeed and satisfactorily complete his daily work on time, and is reflected in the student's sense of achievement in general and his attempt to search for what is new (p81).

It also refers to the tendency to achieve something difficult, master and address difficulties in an attempt to achieve superior standards, to compete and excel over others, and to maximize selfesteem through the use of individual talent (Turki \& Jdaitawi and Sheta, 2018, p147). 
Theoretical definition of motivation to achieve: the desire of the university student to achieve his goals, accomplish his duties and overcome the difficulties faced in his life.

Motivation for achievement is measured procedurally by the degree a student receives on the motivation scale of achievement. Theoretical Guidelines of the Research:

\section{1- Cognitive theory:}

This theory aims to correct misconceptions associated with discordant behavior. (Freeman,1992, p57) It seeks to teach clients to monitor the negative effects of irrational thought, work on their interpretation and start changing the pattern of misconceptions associated with these ideas, thus, changing their quality of life. Then assessing and following up on behavior, using self-talk and teaching cognitive and behavioral skills to confront difficult situations (Kuper, 1996, p98).

Cognitive therapy is moving in a significant direction, introducing the mind and logic into treatment and changing irrational ideas adopted by the client by imposing the modification of his behavior (Al-Nuhi, 1999, p70).

\section{2-Behavioral Theory}

Behaviorism has been a main focus in modern psychology for many decades. It is a trend in psychology in general, and focuses on observable behaviors that are equally important in scientific theory. History behavior has historically formed a departure from Freud's inference and psychoanalytic methods (Cloninger, 2013, p185).

Several researchers and theorists contributed to the development of behavioral theory, which Pavlov and Skinner paid particular attention to. These researchers provided conclusive evidence that behavior is an educated process influenced by the results of the introductions of Pavlov (1928) and the consequences of behavior (by Skinner 1957) (Granillo \& Perron \& Jarman \& Gutowski, 2013, p102).

Behavioral practitioners are characterized by little attention to the client's internal mental processes and their focus on objective, observed and physical behavior. Behavioral practice is also characterized by adherence to the traditional principles of the "scientific method" to help customers get rid of unwanted behaviors or acquire desirable behaviors. Some behavioral scientists refuse to put mental processes into theory because they do not trust any (abstract) concepts as interpretations of ideas, feelings, or behavior. Behavioral practitioners are always interested in empirical evidence (Walsh, 2006, p107). 


\section{Methodology:}

This study belongs to the pattern of descriptive and analytical studies that determine the relationship between two variables, intellectual security and the motivation for achievement of university students. This study relied on the method of the social survey sample.

\section{Study hypothesis:}

1- There are statistically significant differences between the mean scores of male and female university students on the scale of intellectual security in its various dimensions.

2 - There are statistically significant differences between the average scores of male and female university students on the scale of motivation for achievement.

3 - There is a positive statistically significant relationship between intellectual security in its various dimensions (citizenship, religious dimension, intellectual dimension, security dimension, heritage dimension, moral dimension, media dimension) and the motivation for achievement of university students.

\section{Sample :}

The sample frame includes social work students (once year), their numbers were (5315) students, then a purposive sample of (358) students (104) male and (254) female, The sample was selected according to (Stephen Thompson equation) from faculty of social work at helwan university according to the following conditions:

-To be a students of the first year of the faculty of social work.

-Regular students who attend faculty curriculum.

\section{Tools :}

The tools of the study are as follows:

A. A scale of motivation for achievement.

B. A scale of intellectual security.

The following is a description of each scale, its components and dimensions, and the standardization the researcher use in the study: The first scale: The scale of motivation for achievement of adolescents. The two researchers adopted a scale of motivation for achievement of adolescents, amani abdulmaksoud for the year 2014 consists of (15) phrases including negative and positive phrases. The researchers introduced some modifications to the language of some phrases, and an amendment to the content of the phrases, deleting some phrases after the approval of the scale owner. 
The two researchers re-conducted the validity of the scale to verify the suitability of the research. The validity was verified as follows: Validity and Reliability of the Study Tool:

Validity of internal consistency:

The researchers investigated the validity of the measure of motivation for achievement. They used the internal consistency by applying the scale to a sample of (35) students. The correlation coefficients were calculated as follows:

The correlation between the scores of each metric phrase and the total sum of the scale.

Table (1)The correlation coefficients between every item and the total sum of the scale of achievement

\begin{tabular}{|c|c|c|c|c|c|}
\hline $\begin{array}{c}\text { Phrase } \\
\text { number }\end{array}$ & $\begin{array}{c}\text { Correlation } \\
\text { coefficient }\end{array}$ & $\begin{array}{c}\text { Level of } \\
\text { significance }\end{array}$ & $\begin{array}{c}\text { Phrase } \\
\text { number }\end{array}$ & $\begin{array}{c}\text { Correlation } \\
\text { coefficient }\end{array}$ & $\begin{array}{c}\text { Level of } \\
\text { significance }\end{array}$ \\
\hline $\mathbf{1}$ & $\mathbf{0 . 6 6 9}$ & $* *$ & $\mathbf{9}$ & $\mathbf{0 . 6 5 3}$ & $* *$ \\
\hline 2 & $\mathbf{0 . 6 3 0}$ & $* *$ & $\mathbf{1 0}$ & $\mathbf{0 . 4 0 2}$ & $*$ \\
\hline 3 & $\mathbf{0 . 7 1 6}$ & $* *$ & $\mathbf{1 1}$ & $\mathbf{0 . 4 1 7}$ & $*$ \\
\hline 4 & $\mathbf{0 . 8 5 7}$ & $* *$ & $\mathbf{1 2}$ & $\mathbf{0 . 7 3 3}$ & $* *$ \\
\hline $\mathbf{5}$ & $\mathbf{0 . 6 5 8}$ & $* *$ & $\mathbf{1 3}$ & $\mathbf{0 . 4 9 1}$ & $* *$ \\
\hline 6 & $\mathbf{0 . 3 5 9 -}$ & $*$ & $\mathbf{1 4}$ & $\mathbf{0 . 6 9 0}$ & $* *$ \\
\hline 7 & $\mathbf{0 . 4 1 9 -}$ & $*$ & $\mathbf{1 5}$ & $\mathbf{0 . 7 1 6}$ & $* *$ \\
\hline $\mathbf{8}$ & $\mathbf{0 . 4 9 5}$ & $* *$ & \multicolumn{4}{|c|}{ Significant at $(0.05)$} \\
\hline
\end{tabular}

Table (1) shows that the correlation coefficient values are high and function at a significant level of (0.01), (0.05) indicating the validity of the scale to an appropriate degree where the results can be relied upon.

\section{Measurement of scale reliability:}

\section{A) Spilt half reliability:}

The researchers applied the scale to (35) single students. The data was entered using the program (spss) and the phrases were divided into halves; the first half expresses the marital phrases and the other half expresses the individual phrases, and conducted statistical transactions. They found that the coefficient of stability was significant at (0.81), a high coefficient, indicating the stability of the scale and validity of the application.

Correction of scale: -

1. For positive phrases, "always" is given five degrees, "many" is given four, sometimes is given three, "a little" is given two degrees and a " never " is given one. Positive phrase numbers are: 1-2-3-4-5-79-10-12-14. 
2. For "negative" phrases, always is given "one", "many" is given two degrees, sometimes is given three, "little" is given four and never is given five. The negative phrase numbers are: 6-8-11-13-15.

\section{The second scale:}

Scale of intellectual security: -

The research was based on the measure of intellectual security prepared by Dr. Magda El Sayed El-Keshki and Dr. Najwa Thawab Al-Otaibi for Youth 2017. The scale consists of (50) phrases, (37) positive phrases and (13) negative phrases, distributed between seven main dimensions (religious - intellectual - security - heritage - moral media) and the owner of the scale calculated validity and reliability as follows:

A - Validity of the scale

The validity of the scale was verified using two methods; face validity and internal consistency, as follows:

\section{Face validity}

2. Internal consistency:

By calculating the Pearson correlation coefficient between:

A) The degree of every phrase with the total score of the dimension to which it belongs.

B) The score of each phrase with the total score of the scale.

C) The degree of every dimension of the other dimensions with the total score of the scale.

The following tables from (2) to (4) show these results.

Table (2) Shows the values of the Pearson correlation coefficients between the dimensions of the intellectual security scale and the total score of the scale

\begin{tabular}{|c|c|c|c|c|c|c|c|c|}
\hline 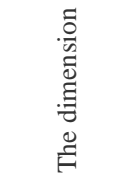 & 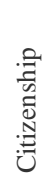 & 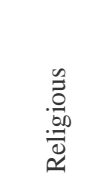 & 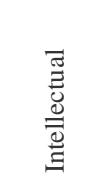 & 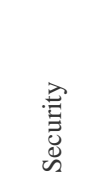 & 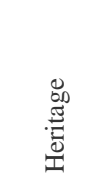 & $\begin{array}{l}\bar{\pi} \\
\sum^{0}\end{array}$ & 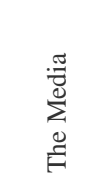 & 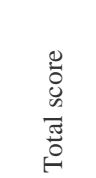 \\
\hline Citizenship & - & $* * 0.686$ & $* * 0.619$ & $* * 0.677$ & $* * 0.757$ & $* * 0.608$ & $* * 0.627$ & $* * 0.689$ \\
\hline Religious & - & - & $* * 0.696$ & $* * 0.722$ & $* * 0.673$ & $* * 0.715$ & $* * 0.627$ & $* * 0.748$ \\
\hline Intellectual & - & - & - & $* * 0.634$ & $* * 0.732$ & $* * 0.687$ & **0.719 & $* * 0.751$ \\
\hline Security & - & - & - & - & *** 0.647 & $* * 0.567$ & *** 0.761 & $* * 0.587$ \\
\hline Heritag & - & - & - & - & & $* * 0.647$ & $* * 0.668$ & $* * 0.686$ \\
\hline Moral & - & - & - & - & & - & $* * 0.647$ & $* * 0.729$ \\
\hline The Media & - & - & - & - & & - & - & $* * 0.698$ \\
\hline
\end{tabular}




\section{Measurement of scale reliability:}

After deleting the phrases that were not related to their dimensions and the total score on the scale - whose numbers have already been mentioned when talking about the validity of the scale - the validity of the scale was verified using the methods of (Alpha Kronbach - alpha) and split half on the sample of the total study (413) for the seven dimensions of each category as well as for the scale as a whole, a reapplication method was also used on a random sample $(\mathrm{n}=137)$.

Table (3) shows the reliability of the intellectual security scale

\begin{tabular}{|l|c|c|c|c|c|c|}
\hline \multirow{2}{*}{ The dimension } & \multirow{2}{*}{$\begin{array}{c}\text { Phrase } \\
\text { number }\end{array}$} & $\begin{array}{c}\text { Alpha } \\
\text { Kronbach } \\
\text { coefficient }\end{array}$ & $\begin{array}{c}\text { Spilt } \\
\text { half }\end{array}$ & $\begin{array}{c}\text { Patch using } \\
\text { Spearman } \\
\text { Brown }\end{array}$ & $\begin{array}{c}\text { Correction using } \\
\text { the Getman } \\
\text { equation }\end{array}$ & \multirow{2}{*}{ Reapply } \\
\hline Citizenship & 6 & 0.916 & 0.718 & 0.836 & 0.800 & 0.871 \\
\hline Religious & 7 & 0.965 & 0.982 & 0.991 & 0.990 & 0.855 \\
\hline Intellectual & 11 & 0.907 & 0.883 & 0.938 & 0.910 & 0.898 \\
\hline Security & 7 & 0.857 & 0.898 & 0.946 & 0.893 & 0.757 \\
\hline Heritage & 6 & 0.939 & 0.925 & 0.961 & 0.941 & 0.839 \\
\hline Moral & 7 & 0.886 & 0.687 & 0.845 & 0.849 & 0.886 \\
\hline Media & 6 & 0.892 & 0.754 & 0.867 & 0.853 & 0.873 \\
\hline $\begin{array}{l}\text { Scale as a } \\
\text { whole }\end{array}$ & 50 & 0.931 & 0.754 & 0.891 & 0.884 & 0.902 \\
\hline
\end{tabular}

The table above shows that the scale of intellectual security has high values that make it a tool for the final application of different groups of young people

\section{Scale correction key:}

After verifying the validity and consistency of the scale, which resulted in the deletion of (13) phrases of the scale in its initial form, the number of phrases of the scale in its final form was (50) of which (37) are positive (13) negative. Five alternatives have been developed to answer each phrase (strongly agree), (ok), (somewhat agree), (disagree) and (strongly disagree) weighted according to their direction. If the direction of the phrase is positive the corresponding scores for the previous alternatives respectively $(1,2,3,4,5)$ If the direction of the phrase is negative, the scores corresponding to the previous alternatives $(5,4,3,2,1)$ indicate a high score on the scale to indicate higher intellectual security of the individual.

\section{Study results:}

The first hypothesis: - There are statistically significant differences between the mean scores of male and female university students on the scale of intellectual security in its various dimensions. 
Table (4) Shows the differences between the average male and female scores on the scale of intellectual security of university students in different dimensions

$$
\mathrm{n}=358
$$

\begin{tabular}{|l|l|l|l|l|l|}
\hline dimension & number & mean & S.D & The value of $\mathrm{t}$ & Level of significance \\
\hline Males & 104 & 195.38 & 18.499 & \multirow{2}{*}{$* 2.954$} & \multirow{2}{*}{0.05} \\
\hline Females & 254 & 188.86 & 20.024 & & \\
\hline
\end{tabular}

The table above shows that there are statistically significant differences between the average male and female scores on the scale of intellectual security of university students in its various dimensions in favor of males, thus proving the first hypothesis of research.

The second hypothesis: - There are statistically significant differences between the average scores of male and female university students on the scale of motivation for achievement.

Table (5) It shows the differences between the average male and female scores on the motivation scale of achievement for university students

\begin{tabular}{|l|l|l|l|l|l|}
\hline dimensions & number & mean & S.D & The value of $\mathrm{t}$ & Level of significance \\
\hline Males & 104 & 45.65 & 5.422 & \multirow{2}{*}{0.630} & \multirow{2}{*}{ Non-Significant } \\
\hline Females & 254 & 46.07 & 5.608 & & \\
\hline
\end{tabular}

The table above shows that there are no statistically significant differences between the average scores of males and females on the motivation scale of achievement for university students and thus proving the second hypothesis of the study was not valid.

The third hypothesis: - There is a positive statistically significant relationship between intellectual security in its various dimensions (citizenship, religious dimension, intellectual dimension, security dimension, heritage dimension, moral dimension, media dimension) and the motivation for achievement of university students.

Table (6) Shows the relationship between intellectual security in its various dimensions (citizenship, religious, intellectual, security, heritage, ethical, media) and motivation for achievement of university students

\begin{tabular}{|l|c|l|}
\hline Dimensions & Motivation for achievement & Significance level \\
\hline Citizenship & $* * 0.341$ & Significant0.01 \\
\hline Religious & $* 0.127$ & Significant 0.05 \\
\hline Intellectual & 0.061 & Non-Significant \\
\hline Security & 0.014 & Non-Significant \\
\hline Heritage & 0.103 & Non-Significant \\
\hline Moral of & $* * 0.265$ & Significant 0.01 \\
\hline Media security \\
$\begin{array}{l}\text { A measure } \\
\text { intellectual } \\
\text { as a whole }\end{array}$ & 0.092 & Non-Significant \\
\hline
\end{tabular}


The table above shows that there is a statistically significant relationship between the dimension of citizenship and motivation for achievement at the level of significance of (0.01), and there is a statistically significant relationship between the religious dimension and motivation for achievement at the level of significance of (0.05) while there is no statistically significant relationship between the intellectual dimension and motivation for achievement in university students. There is no statistically significant relationship between the security dimension and motivation for achievement, and there is no statistically significant relationship between the heritage dimension and motivation for achievement, while there is a statistically significant relationship between the moral dimension and motivation for achievement at the level of significance of (0.01). There is no statistically significant relationship between the dimension of media and motivation for achievement of university students, but there is a statistically significant relationship between security and intellectual achievement motivation among university students at the abstract level of (0.01). Thus proving the third hypothesis of the study.

\section{Discussion:}

The current study found that there are statistically significant differences between the mean scores of males and females on the scale of intellectual security of the university youth in its various dimensions in favour of males. This result is attributed to a study (Ali, 2017) where it was discovered along with the presence of statistically significant differences between male and female students in the intellectual security variable. However, these differences are in favor of females, and this is consistent with the theoretical framework that achieving intellectual security among students (males and females) would have a positive impact on society (Al-Ghamdi, 2012, p 237), and confirmed by the theory. The basic assumption of treatment is that thinking constitutes behavior, and that what the individual thinks and says to himself shapes his attitudes and is closely related to his accepted behavior (Alnoohi, 1999, p70). The study of (Mohamed, 2013) also referred to the role of the university in promoting the concept of intellectual security among university students and highlighting the role of the faculty member to activate intellectual security during the consolidation of the principles of moderation in their beliefs, actions and words.

The study also concluded that there are no statistically significant differences between the mean scores of males and females, and this is consistent with the results of (Al-Ahmed, 2017) (Turki\& Jdaitawi and Sheta, 2018) and (Hussein, 2017). In the absence of significant differences on the measure of motivation for achievement among university students according to the gender variable, it disagreed with the (Naik \& Ahirrao, 2018) study which found statistically significant 
differences in the levels of motivation for achievement in both sexes. This was confirmed by the research theory that behavioral theory believes behavior is only visible and is learned by the university students from their environment in which he lives and becomes a frequent habit through reinforcement and modeling. Behavior is an educated process influenced by the results of introductions Behavior and Consequences (Granillo \& Perron \& Jarman \& Gutowski, 2013, p 102). Also, the study by (Mohamed, 2013) highlighted the role of the faculty member in activating intellectual security, and his keenness to educate students with good intellectual education through the establishment of the principles of restraint and moderation in their beliefs, actions and words, which have a positive impact on the behavior of university students (motivation for achievement).

In addition, the results of the current study show that Motivation for achievement of university students reached a level of significance of (0.01), and also reached a statistically significant relationship between the dimension of citizenship and motivation for achievement at the level of significance of (0.01) This result is consistent with the study of (Arab, 2018), which aimed to identify the nature of the relationship between belonging and intellectual security of university students, the results of which found a correlation of statistical significance between national belonging and intellectual security. While the result of the current study differed with the result of (Awad, 2017) which aimed to identify the role of the group worker in enhancing the national identity of university youth and identifying the mechanisms used by the social worker to enhance the intellectual security of young people. The results of the study showed that the majority of the sample of the study are not interested in the activities of the committees of the Union and don't participate in them, their focus is on academic achievement in preparation for graduation and this indicates a low national identity among university students. The result differs from the results of the studies of (Al-Hazani, 2016), and (Jad \& Ahmad, 2019), which found a statistically significant relationship between the use of social networking sites and intellectual security of university students.

- Indicators of the role of social workers in promoting intellectual security and motivation for achievement amongst university students:

In the light of the results of the current research, the two researchers tried to reach indicators for the role of the social worker to promote intellectual security and motivation for achievement among university students. Perhaps the most important of these indicators: 


\section{(1) With regard to intellectual security:}

- Work to enhance the intellectual security of students through cooperation with the Department of Youth Welfare faculty through the work of seminars, workshops and training courses in the Information Technology Unit, and urge students to participate in mobile activities to enhance the heritage and ethical dimensions through scientific trips to archaeological sites, strengthening the values of cooperation and participation among students, reinforcing the moral aspect.

- Urge students to participate in the activities of student unions to promote identity and national belonging.

- Urge students to participate in scientific research such as the Egyptian Knowledge Bank through the University's digital library to enhance the intellectual and media security of students.

- The Complaints and Proposals Unit in the faculty assist students to solve their problems and escalate their complaints to the concerned faculty in order to enhance the security dimension of the students.

- The Center prepares research and training leaders in the faculty to strengthen the intellectual security of students through the work of training courses and workshops.

\section{(2) Regarding student motivation for achievement}

- The faculty member plays an active role in promoting student behaviors within the classroom in order to create a desire for achievement, whether at the academic level or the level of life in general.

- The Environment Agency for Education and Student Affairs make promotional trips for students who excel academically and ethically, which enhances their motivation for achievement.

- The Vice-Deanship of Education and Student Affairs to raise the grants of excellence for outstanding students.

- The social treatment center in the college helps students solve their problems and increases their ability to make decisions related to their affairs.

\section{Research proposals:}

- The effectiveness of rational emotional behavioral therapy in enhancing the intellectual security of university students.

- The effectiveness of the model in focussing on behavioral tasks for the development of motivation in university students.

The difficulties faced by researchers during the practical application are as follows:

- Some students are worried about filling the scale of intellectual security because of the lack of awareness of this issue and view it as a political aspect only.

- Researchers turned to the research community more than once to meet the scale due to the students' preoccupation with the lectures. 


\section{Reference}

Al-Ahmad. A. (2017). The relationship between motivation of achievement and superstitious thinking in a sample of students of the Faculty of Education in Damascus, a research published in the Journal of the Union of Arab Universities for Education and Psychology, Vol. 15, No. 2, pp. 1453.

Al-Anani. H. (2013). Educational Psychology, Amman, Dar Al-Fikr, p216

Al-Ghamdi. A. (2010). The values of citizenship among secondary students and their relationship to intellectual security, Riyadh, Center for Studies and Research, p.237.

Al-Hazani B. N. (2017). Research published in King Fahd National Library Magazine, vol. 23, 14, October 2016 Social networks and their impact on enhancing the intellectual security of students of Princess Noura bint Abdul Rahman University, March.

Al-Hoshi.M. Y. (2017). Enhancing Intellectual Security in the Light of Contemporary International Models and Experiences of Dialogue Narrowing the Secondary Stage in Riyadh City, King Fahd National Library for Publishing, Riyadh, 3rd Floor, p. 25.

Ali. A. (2017) Intellectual Security and its Relationship with Emotional Intelligence and Decision Making among Cairo University Students, Journal of Psychological Counseling, Ain Shams University, Psychological Counseling Center, p. 52, December, pp. 143: 202.

Al-Khathlan. B. N (2017). A Proposed Concept for Using Electronic Communication Tools in Achieving the Intellectual Security of Youth in Higher Education Institutions, a research published in the International Journal of Specialized Education, Vol. 6, No. 8, p. 68.

al-Khatib. M. (2015). intellectual deviation and its relationship to national security, Riyadh, Dar Bin Hazima.

Al-Wahsh. M. H. (2018). A Proposed Perception of the Role of Faculty Members in Promoting the Intellectual Security of Students of the University of Bish, Research Published in the Journal of Educational Sciences, No. 2, Vol. 2, April 2018, pp. 122: 181.

Arab. H. A. (2018). Social responsibility and its relationship to national belonging and intellectual security in a sample of students and levels of King Abdul Aziz University, Journal of the Faculty of Education, Assiut University, Faculty of Education, vol 34, p 2, February 2018, 92-113.

Awad. G. A. (2017). Towards a Proposed Concept of the Role of the Community Specialist to Enhance the Intellectual Security of University Youth, A Study Applied to Students at the Higher Institute of Social Work in Aswan, Journal of Social Work, Egyptian Society of Social Workers, Egypt.

Berdnikova. D. (2018). "Psychological Correlates of Achievement Motivation on the Personal-meaning Level" in The Fifth International Luria Memorial Congress «Lurian Approach in International Psychological 5cience», KnE Life Sciences, pages 151-162. Page 151 DOI 10.185027kls.v4i8.3272 CAPMAS, (2018)

Elnouhy. F. A. (1999), "Theories of Individual Service (Individual Behavioral Service)", Cairo, the first book of the series towards the development of social welfare, House of Culture Press, 3rd edition.

Ghanimat. A. K, Olaimat. R. A.(2012). Research published in the Journal of the Islamic University for Educational and Psychological Studies, Volume 20, No. 2, June, p. 23: 51. 
Hussein. I. A. (2017). Motivation of achievement and its relationship with future ideas among university students, Journal of the Faculty of Education, University of Mustansiriya, p II, pp. 121: 148.

Jaj, Y.A., Ahmad, I.S. (2019). The relationship between the use of Social Networking sites and intellectual security among students of social work, Egyptian journal of social work (EJSW), vol(8), Issue 1.

Mansour.A.M.(2017). Assessing the Role of the University in Achieving the Intellectual Security of its Students from their Perspectives and Faculty Members, Research published in the Journal of the Faculty of Education, Al-Azhar University, No. 172, Part I, January, pp. 587: 638.

Mohamed.A.F. (2015). Satisfaction of counseling needs and its relationship with both satisfaction with academic guidance and motivation of academic achievement among university students, Journal of Studies in Social Work and Humanities, Helwan University, Faculty of Social Work, 2015, No. 39, Vol. 1, October, p. $71-150$.

Mohamed. R. A. (2013). The role of the university in activating the educational intellectual security of its students - a field study, Educational Journal, Faculty of Education, Egypt, Sohag University, No. 33.

Mohamed. R. A. (2013). The role of the university in the activation of intellectual security for its students a field study, Educational Journal, Sohag University, Faculty of Education, No. 33, January, p 80: 140

Naik, D., \& Ahirrao, K. D. (2018). Emotional intelligence and achievement motivation among college students. Indian Journal of Health \& Wellbeing, 9(1), 86-88. fromhttp://search.ebscohost.com/login.aspx?direct=true $\& \mathrm{db}=\mathrm{a} 9 \mathrm{~h} \& \mathrm{AN}=12764525$ $1 \&$ site=ehost-live

Salem.H, Kebshour Koko Kambil. K, Al-Khalifa. H. O. (2012). Achievement Motivation Relationship with Discipline, Level of Ambition, and Academic Achievement among Students of Higher Education Institutions in Sudan, Research Published in the Arab Journal for Developing Excellence, No. 4, Volume 3, p. Pp. 81: 96.

Turki, F. J., jdaitawi, M and sheta, H. (2018). Fostering positive adjustment behaviour: Social connectedness, achievement motivation and emotional-social learning among male and female university students Active Learning in Higher Education 2018, Vol. 19(2) 145-158.

Cloninger ' S. (2013). Theories of personality understanding persons، 6th Ed, N. Y person.

Fahmy S. M. (2012). Crisis Management with Youth, Alexandria, Modern University Office.

Freeman, Davis.: (1992). Cognitive the theory of personality disorders, internationalhand book in behavior modification, Now York, plenum

Granillo, M. T., Perron, B.E., Jarman, C., \& Gutowski, S.M. (2013). Cognitive Behavioral Therapy with Substance Use Disorders. In M.G. Vaughn\& B.E. Perron (ed.) Social work, practice in the Addictions, New York springer.

Kuper, Adam, Jessica, (1996). The social science encyclopedia, London, British Library, second edition

Walsh, J. (2006). Theories for direct social work practice, N.Y Brooks / Cole.

Zaher. M. A. (2018). Motivation of achievement and its relationship to the spiritual intelligence of students of the Faculty of Education at King Khalid University, the Arab Journal of Educational and Social Studies, p. 12, January, pp. 213-237 